\title{
Is the Private Sector more Productive than the Public Sector?
}

\author{
KHWAJA SARMAD
}

\section{INTRODUCTION}

In developing countries the rapid growth of the public sector during the past few decades was viewed as an important means for accelerating the pace of economic growth. In most developing countries the public sector now accounts for a prominent share of total production and investment. But the contribution of the public sector to growth has been much below expectations. In many cases public enterprises require large subsidies from the government and impose a significant fiscal burden on the economy, which leads to the notion that the private sector is much more productive than the public sector. However, little empirical work has been done in this field so that the proposals that emphasize the private sector vis-a-vis the public sector rest largely on theoretical considerations.

Recent work by Khan and Reinhart (1990) is an important exception. Using cross-section data for the seventies of 24 developing countries they show that the arguments favouring the private sector in adjustment programmes have empirical support. Khan and Reinhart estimate a growth model in which the effect of private and public investment on growth is separated. A comparison of the marginal productivities of the two types of investment allows them to conclude that "all in all, there does seem to be some merit in the key role assigned to private investment in the development process by supporters of market-based strategies". [Khan and Reinhart (1990), p. 25.]

However, their period is rather short and the coverage limited so it seems useful to extend the scope of their study. First, the sample of developing countries could be enlarged. Given the lack of consistent long-run data on the institutional breakdown of aggregate investment this source of extension is limited, but the available data do allow the relevant hypothesis to be tested for a different set of 
developing countries. ${ }^{1}$ Second, given the availability of more recent data on public and private investment it would be interesting to examine how the influence of private and public sector investments on economic performance has changed during different time periods. Third, given that cross-section analysis is usually faced with the problem of heteroscedasticity, it would be worthwhile to test their assumption of homoscedasticity.

Section 2 of this paper sets out the methodology for estimating the direct effects on growth of public and private investment. The estimation results are set out in Section 3. Finally, some conclusions are presented in Section 4.

\section{THE METHODOLOGY}

The starting point of the growth methodology (the analysis here follows that of Khan and Reinhart (1990) is the assumption that production in an economy is characterized by the following production function:

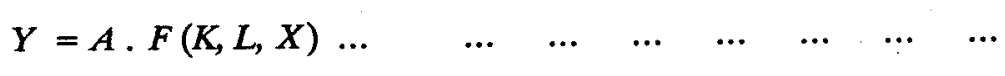

where $Y$ is the level of real output, $A$ measures factor productivity, $K$ and $L$ are capital and labour inputs and $X$ is exports. The partial derivatives of $Q$ with respect to $K, L, X$ and $A$ are assumed to be greater than 0 . The presence of $X$ as an argument in Equation (1) is justified on grounds that exports raise productivity of domestic production [see e.g. Balassa (1978); Tyler (1981); Kavoussi (1988) and Ram (1985)]. Khan and Reinhart use exports and imports (representing imported inputs) alternatively as an independent variable. In this study we focus on exports because relevant data on imported inputs is not available and because exports are likely to have a much greater impact on domestic production economies. Expressing Equation (1) in growth terms yields the following:

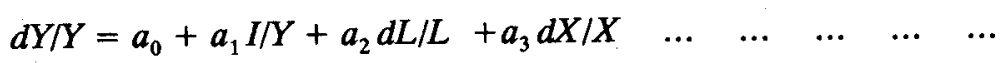

where:

$a_{0}$ measures productivity growth assumed to be constant, $a_{1}$ is the marginal product

${ }^{1}$ We include in our cross-section sample of developing countries (for the years 1980-87) the following countries not represented in Khan and Reinharts' study. Bangladesh, India, Kenya, Nigeria, Pakistan, Peru, Philippines, Tunisia, Uruguay, Zambia and Zimbabwe (but because of lack of appropriate data the following countries in their study could not be accounted for:Dominican Republic, Haiti, Honduras, Panama, Paraguay, Venezuela, Barbados, Trinidad and Tabago, and Singapore. For the period 1970-1979 the sample of countries included the following: Argentina, Bolivia, Brazil, Chile, Colombia, Ecuador, Guatemala, India, Kenya, Mexico, Pakistan, Thailand, Tunisia, Turkey, and Uruguay. The data for the relevant variables are averages for the respective periods. 
of capital, $I=d K, a_{2}$ and $a_{3}$ are the elasticities of output with respect to labour and exports.

By substituting for the variable (equal to $K_{p}+K_{g}$ i.e. the sum of the stock of private and public capital) in Equation (1) and following the same procedure as in deriving Equation (2) Khan and Reinhart derive the following equation:

$$
d Y / Y=b_{0}+b_{1} I_{p} / Y+b_{2} I_{8} Y+b_{3} d L / L+b_{4} d X / X \ldots \quad \ldots \quad \ldots
$$

where:

$I_{P} / Y$ and $I_{g} / Y$ are the investment rates of private and public investment and $b_{1}$ and $b_{2}$ are the corresponding marginal productivities.

A comparison of the coefficients $b_{1}$ and $b_{2}$ in Equation (3) provides an indication of the differential effects of private and public investment on growth of aggregate output. However, as noted above this comparison has to be made with caution because the methodology does not account for the indirect effects of public investment.

\section{RESULTS OF ESTIMATION}

Following Khan and Reinhart we estimate Equation (3) using ordinary least squares for a cross-section sample of 26 countries on the basis of data averages for the period 1980 to 1987 . We also estimated Equation (3) for a cross-section sample of 15 countries (for which relevant data was available) on the basis of data averages for the period 1970 to 1979 to compare our results with those of Khan and Reinhart. Data relating to real GDP, investment and exports has been taken from the World Tables data tape of the World Bank. Total investment is split into public and private investment according to the sectoral breakdown in Pfeffermann and Madarassy (1989), and data on labour has been obtained from the data diskette (MEDS) of the UN Statistical Office. The results of estimation are reported in Table 1.

Several observations can be made on the basis of the results reported in Table 1. First, the fits of the Equations are satisfactory and most of the variables are significant at the 95 percent confidence level. The important exceptions are the public investment variable in Equations (2) and (3) and the labour growth variable in Equations (1) and (2). Second, in general, the estimated coefficients in Equations (1) and (2) have the correct signs and the values are consistent with those reported by Khan and Reinhart. Note, for example, that in Equation (1) (estimation period 1980-1987) the coefficient of the exports variable is significant 
Table 1

Results of Estimation\#

\begin{tabular}{|c|c|c|c|c|c|c|c|}
\hline \multirow[b]{2}{*}{ No. } & \multirow[b]{2}{*}{ Constant } & \multicolumn{2}{|c|}{ Investment } & \multicolumn{2}{|c|}{ Growth of } & \multirow[b]{2}{*}{$R^{2}$} & \multirow[b]{2}{*}{ SEE } \\
\hline & & Private & Public & Labour & $\overline{\text { Exports }}$ & & \\
\hline
\end{tabular}

$$
1980-1987^{*}
$$

\begin{tabular}{|c|c|c|c|c|c|}
\hline $\begin{array}{c}-0.021 \\
(1.60)\end{array}$ & $\begin{array}{c}0.161 \\
(2.62)\end{array}$ & $\begin{array}{r}0.263 \\
(3.05)\end{array}$ & $\begin{array}{r}-0.011 \\
(0.03)\end{array}$ & $\begin{array}{r}0.147 \\
(3.03)\end{array}$ & 0.703 \\
\hline
\end{tabular}

$1970-1979^{* *}$

\begin{tabular}{|c|c|c|c|c|c|}
\hline $\begin{array}{r}-0.007 \\
(0.43)\end{array}$ & $\begin{array}{c}0.214 \\
(2.12)\end{array}$ & $\begin{array}{r}0.019 \\
(0.15)\end{array}$ & $\begin{array}{c}0.742 \\
(1.50)\end{array}$ & $\begin{array}{c}0.176 \\
(2.02)\end{array}$ & 0.691 \\
\hline
\end{tabular}

Khan and Reinhart's Results $1970-1979 * *$

$\begin{array}{rrrrrrr}2.145 & 0.158 & -0.108 & 0.573 & 0.163 & 0.737 & 1.091 \\ (1.66) & (3.27) & (1.02) & (1.94) & (3.75) & & \end{array}$

\# The values in parentheses are $t$-values; $R^{2}$ is the coefficient of determination; and SEE is the standard error of the equations.

- Sample size is 15.

** Sample size is 26 .

*** Sample size is 24 .

and fairly large-indicating, the importance of export expansion as a determinant of economic performance. These results present additional empirical evidence confirming a significant cross-country association between export expansion and economic performance [see e.g. Balassa (1978); Tyler (1981); Kavoussi (1984); and Ram ،(1985)]. In Equations (1) and (2) productivity growth estimates (represented by the respective constants) remain negative but come close to being statistically different from zero at the 5 percent level. This coefficient summarizes the influence of all other variables affecting total factor productivity as well as that of the error term. Third, and more importantly for the purposes of this study, in Equation (2) the coefficient of public investment-marginal productivity of public sector capital-is statistically insignificant. Thus, at face value confirming Khan and Reinharts' result Equation (3) that during the years from 1970-1979 public sector investment did not significantly influence economic performance in developing countries. Fourth, the empirical estimates obtained for the period 1980-1987 are different from the general pattern observed during the earlier period, particularly with regard to the investment variables: The coefficient of 
public sector investment is significant at the 99 percent level and is quite large in comparison with the earlier period. Its value is much greater than the coefficients of the other variables in the model and, more importantly, exceeds the value of the private sector investment coefficient, which is positive and statistically significant.

A growth accounting exercise on the basis of Equations (1) and (2) shows that the pattern of factor contribution to overall growth has changed markedly in the eighties as compared with the decade of the seventies. The most noticeable change is in the contribution of public investment, which now accounts for almost half of total growth as compared with 37 percent of the total in the case of private investment. The contribution of exports is substantial and has remained stable around 14 percent throughout the two periods. However, the contribution of labour has suffered in the eighties declining from 32 percent in the earlier period.

An important problem in the estimation of production functions of the type above relates to the possibility of rejecting the underlying homogeneity assumption. We check for the presence of heteroscedasticity in the estimation of Equation (1) in Table 1 which may arise because of non-homogeneity of the production function across countries or because of omission of significant explanatory variables, either of which can lead to inefficient estimates and to faulty inferences. For this purpose we subjected Equation (1) to the [White test White, $(1980)]^{2}$ yielding a value of 0.73 for the test statistic which is too small, in comparison with the corresponding critical $X^{2}$ values at the 5 percent and 10 percent levels, to justify the rejection of the null hypothesis of no heteroscedasticity. This suggests that the feedback from the dependant to the independent variables appears to be small thus providing some basis about the validity of the regression estimates in Table $1^{3}$

2This involves the estimation of the following equation:

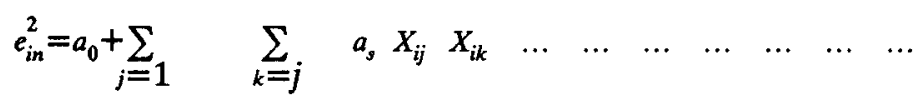

where the a's are the parameters to be estimated by OLS, $e^{2}$ in is the squared estimated residuals for the $i$ th observation in the estimated regression model and the variables on the right side are the second order product and cross products of the original regressors. The test statistic $n R^{2}$ is distributed as $X^{2}$ with degrees of freedom equal to the number of variables on the right side of the above equation, where $N$ is the number of observations and $R^{2}$ is the coefficient of determination estimated from the equation.

${ }^{3}$ As noted above one of the problems of the methodology is that it does not account for the indirect effects of public investment. One way of estimating this is with the help of the following investment function 


\section{CONCLUSION}

Using data of the 1970s and 1980s for a cross-section of developing countries this paper has shown, mainly, that the role of public investment in the growth process in developing countries appears to be no less important than that of private investment, though the pattern of public investment contribution to growth has changed significantly during the past two decades. The data for the 1980s indicates that the direct effects of public sector investment alone outweigh those of private investment. Furthermore, the paper also confirms the findings in earlier empirical literature on the positive association between export and import growth and productivity increases.

\section{- Continued}

where:

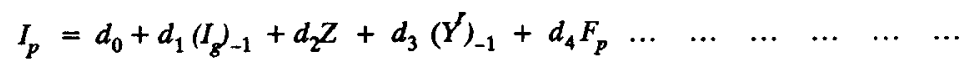

$I_{p}$ and $I_{g}$ are the investment rates for private and public investment. The coefficient of $\left(I_{p}\right)_{-1}$ i.e. public investment lagged by a year, $d_{1}$ will measure the 'crowding-in' effect on private investment. This is expected to be positive (i.e. $d_{1}>0$ ). $Z$ is net resource transfer from the private to the public sector that results expost from the various means used to finance the budget deficit and state enterprise capital requirements, including bond sales, bank credit, monetary emission etc. It is derived as the difference between the fiscal deficit and the inflow of foreign capital to the public sector (for details of derivation and accounting framework [see Fitzgerald and Sarmad (1990)]. The coefficient of $Z, d_{2}$ is a measure of 'crowding-out'. Since $Z$ constitutes a financial constraint on the implementation of private sector investment plans $d_{2}$ is expected to be $<0$. In case $d_{2}$ is not significantly different from 0 i.e. rejection of the hypothesis of no crowding-out, it would be worthwhile to test the converse hypothesis of crowdingout of consumption to shed light on the underlying adjustment mechanism. $Y^{\prime}$ is the growth of output lagged to reflect the standard effect of demand growth on investment; and $F_{p}$ is net foreign capital inflow into the private sector which as a supplemental source of funding is expected to have a positive effect on $I_{p}$ i.e. $d_{4}>0$.

To explore the linkage between public investment and private investment we estimated Equation (5) by means of ordinary least squares on the basis of time series data for Pakistan for the years 1970-88. The coefficient of lagged GDP growth was not significantly different from 0 at the 5 percent level. Reestimating Equation (4) with a new variable in the specification $\left(I_{p}\right)_{-1}$ (the rate of private investment lagged by a year) yielded the following result:

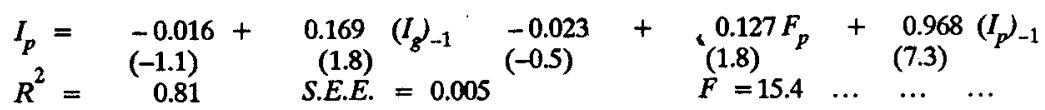

All the variables in Equation (6) have the expected signs and except for the coefficient of $Z$ are significantly different from 0 at the 5 percent level. The coefficient of $\left(I_{p}\right)_{-1}$ is positive. $F_{p}$ has a positive effect on private investment reflecting its role as a source of supplemental finance. But it is the coefficients of $\left(I_{g}\right)_{-1}$ and $Z$ which are of most interest to us. The former reflects a positive influence of public investment on private investment. The coefficient of $Z$ which is not significantly different from 0 implies that resource transfer from the private to the public sector does not significantly influence private sector investment intentions suggesting the rejection of the 'crowding-out' hypothesis. A preliminary investigation of the relationship between private savings rate and the variable $Z$ showed a high positive correlation between the two variables. This suggests that instead of private investment being crowded out private consumption appears to have adjusted to generate the higher savings for the increased resource transfer from the private to the public sector. This is a useful result and merits further investigation. For our purpose it will suffice to note that resource transfer from the private to the public sector does not appear to crowd-out private investment. 
On the face value of the empirical estimates there appears to be little doubt that public sector investment has begun to exert a significant influence on aggregate output. This would suggest abandoning the conventional notions that public investment is not important to economic growth in developing countries, or that it is substantially less important as compared with private investment.

However, given the limitations of the methodology and the special circumstances of the two periods examined here these results need to be interpreted with caution. It could be argued, for example, that the easy availability of external finance during the first period and its use in some of the developing countries included in the sample, in long gestation, and in many cases unproductive, projects negatively affected the contribution of the public sector to aggregate growth. On the other hand, during the second period, the strain of macro-economic adjustment could have made public sector performance more important to economic growth. Alternatively, it could be argued that fast growing countries had better access to external finance and could thus afford a higher level of public investment. Thus, while the above analysis has served to uncover some interesting behavioural patterns of public and private sector investment during the decades of the seventies and eighties and provides a useful reference point for analysing individual country experience, it should be supplemented by detailed country studies to reveal the country-specific factors involved in the behavioural shifts over time.

\section{REFERENCES}

Balassa, Bela (1978) Exports and Economic Growth: Further Evidence. Joumal of Development Economics $5: 2$ 181-189.

Fitzgerald, E.V. K., and Khwaja Sarmad (1990) Public and Private Sector Capital Account Behaviour in LDCs 1970-1988. Sub-series on Money, Finance and Development The Hague: ISS. (Working Paper No. 36.)

Kavoussi, Rostam M. (1988) Export Expansion and Economic Growth: Further Empirical Evidence. Joumal of Development Economics 14 : 241-250 Khan, Mohsin S., and Carmen M. Reinhart (1990) Private Investment and Economic Growth in Developing Countries. World Development 18 : 1 19-27. Pfeffermann, Guy P., and Andrea Madarassy (1989) Trends in Private investment in Thirty Developing Countries. Washington, D. C.: International Finance Corporation. The World Bank. (Discussion Paper No. 6.)

Ram, Rati (1985) Exports and Economic Growth: Some Additional Evidence. Economic Development and Cultural Change 33 : 1 415-425. Tyler, William G. (1981) Growth and Export Expansion in Developing Countries: Some Empirical Evidence. Joumal of Development Economics 9 : 1 121-130. 


\section{Comments on}

\section{"Is the Private Sector more Productive than}

\section{the Public Sector?"}

Dr Sarmad's empirical paper on the relative productivity of the public vis-a-vis the private sector is very interesting and well timed. He had used recent data (of the eighties) and considered also the indirect effects of public investment on growth, which leads him to different conclusions from that of earlier studies. There are a few queries, though:

(1) Does the presence of Exports (x) as an argument in the production function lead to a differential increase in the productivity of the public relative to the private sector, and if so, does it lead to an upward bias in estimating the marginal productivity of public investment, and hence the effect of public investment on growth;

(2) My second query concerns the variable $Z$ in Equation (4) the net resource transfer from the private to the public sector-and its coefficient $d_{2}$ which is a measure of crowding out. Will the sign of $d_{2}$ always be $<0$ and will it not depend on how the budget deficit is financedmoney supply, bonds or taxation. The first of these alternatives, i.e., the increase in money supply may well lead to zero crowding out and no fall in private investment due to the budget deficit;

(3) The coefficient of public sector investment-marginal productivity of public sector capital is different in two time periods 1970-1979 and 1980-1987. In the latter period analysis, it is statistically significant and greater and exceeds the value of the private sector investment coefficient. What accounts for this difference in the time periods? Is it just the increase in the size of the public sector, or strains of macro economic adjustment, and how?

(4) The results of estimation of the investment function show that $z-$ resource transfer from the private to the public sector-does not significantly influence private sector investment implying a rejection of the crowding out hypothesis. The reason given is that private consumption adjusted to facilitate higher savings. Does this hold in the face of ostentatious consumption patterns that we observe, the demonstration 
effect, as well as the low interest rate responsiveness of consumption? and

(5) Conclusions about reductions in size of public sector adversely affecting output growth and productivity of private sector cannot be made if the analysis is divorced from the question of resource allocation and inefficiency within the private sector. That is also a type of indirect effect of public investment and needs to be taken into account with the other two indirect effects that the author handles so well.

University of the South Swanee,

Yasmeen Mohiuddin USA. 